Д. М. Главчев

Національний технічний університет «Харківський політехнічний інститут», Харків, Україна

\title{
ПРОГРАМНІ КОМПОНЕНТИ БОРТОВОЇ КОМП'ЮТЕРНОЇ СИСТЕМИ ДИЗЕЛЬ-ПОТЯГА
}

\begin{abstract}
При вирішенні завдань в рамках геометричної теорії управління виникають проблеми, пов'язані зі складністю виконання розрахунку похідних Лі, перевірки розподілень на інволютивність, пошуку функцій перетворення, які пов' язують змінні та рівняння лінійної та нелінійної моделей. При виконанні цих операцій людиною виникає потреба у виконанні занадто об' ємних аналітичних розрахунків які можуть стати причиною відмови від застосування геометричної теорії управління. Вирішити цю проблему можна за допомогою використання спеціалізованого програмного забезпечення, що розглядається як програмне забезпечення для бортової комп'ютерної системи дизель-потяга, яке здатне автоматизувати необхідні розрахунки, чим істотно скоротити час виконання лінеаризації та пошуку функцій перетворення для математичних моделей за рахунок використання потужностей комп'ютерної техніки та нейронних мереж. Метою роботи $є$ розробка спеціалізованого програмного забезпечення для виконання лінеаризації математичних моделей та пошуку функцій перетворення за рахунок використання нейронних мереж та можливостей мови програмування, що має графічний інтерфейс для взаємодії з користувачем. Результати. За допомогою можливостей сучасних мов програмування на основі запропонованих алгоритмів обробки даних та нейронних мереж запропонованої структури, розроблено спеціалізоване програмне забезпечення для виконання перетворення нелінійних математичних моделей у лінійну форму Бруновського та пошуку функцій перетворення. При використанні розробленого програмного забезпечення збільшується швидкість виконання процесу лінеаризації, пошуку функцій перетворення, а графічний інтерфейс та коментарі, які висвітлює програмне забезпечення в процесі роботи дають можливість оперувати користувачам, які не мають спеціальної підготовки. Порівняння результатів моделювання нелінійної математичної моделі з лінійною математичною моделлю у формі Бруновського показало повне співпадіння та підтвердило правильність теоретичних положень та еквівалентність нелінійної та лінійної моделей. Висновки. Розроблено спеціалізоване програмне забезпечення для автоматизації аналітичних перетворень геометричної теорії управління, вирішення систем рівнянь в часткових похідних, для визначення функцій перетворень, що зв'язують змінні лінійної та нелінійної моделей. Промодельовано ряд об' єктів, які показали працездатність програмного забезпечення.
\end{abstract}

Ключов і слов а: програмне забезпечення, форма Бруновського, математична модель, нейронні мережі, геометрична теорія управління.

\section{Постановка проблеми і аналіз літератури}

Розвиток залізничної галузі в Україні потребує створення системи підтримки прийняття рішень машиніста та системи автомашиніста. Адже в високорозвинених країнах Америки та Свропи завантаженість залізничних шляхів $€$ досить високою, проте використання спеціалізованих систем управління допомагають вирішити питання оптимального руху потяга по маршруту його слідування 3 урахуванням факторів що впливають на нього: розклад руху, профіль шляху, особливості залізничного полотна, погодні умови, тощо. В нашій країні цього поки що немає, але питання створення аналогічних систем на потягах вітчизняного виробництва вже стоїть досить гостро. Адже сьогодні не можна покладатися лише на досвід машиніста, необхідно використовувати науковий підхід для виконання відповідних розрахунків, результати яких будуть перетворенні в нормальну для сприйняття людиною форму, та надаватимуть машиністу підказки, в залежності від поточної ситуації на маршруті. В перспективі дані системи можуть бути модернізовані до систем автоматичного ведення потяга $[1-8]$. Але, як і в будь-якому напрямку розвитку технологій, тут існують певні обмеження, адже процеси руху рухомого складу більш-менш точно описуються за допомогою систем звичайних нелінійних диференційних рівнянь високого порядку, то визначення оптимальних законів управління в реальному часі є декілька ускладненим. Лінеаризація по Тейлору таких систем рівнянь дозволяє отримати системи лінійних рівнянь, но тільки на окремих точках, що не дозволяе визначити оптимальні закони управління тяговим рухомим складом під час його прямування. Однак, привабливість добре розробленої теорії лінійних систем управління призвела до створення геометричної теорії управління, яка дозволяс отримати системи нелінійних рівнянь, що будуть еквівалентними початковим нелінійним системам рівнянь в усій області змін змінних початкового нелінійного об'єкта управління. [1, 3, 6 -8].

Труднощі, пов'язані з синтезом оптимальних систем управління для нелінійних об'єктів, зіграли важливу роль в розробці методів лінеаризації нелінійних систем, 3 подальшим застосуванням до них теорії лінійних систем управління. Однак, в даному випадку також існують обмеження. Нажаль, лінеаризація по Тейлору, яка найчастіше застосовується, обмежена лише лінеаризацією невеликої частини простору навколо обраної робочої точки, а це не дає можливості застосовувати ії для лінеаризації складних об’єктів, таких як дизель-потяг $[1,3]$. Однак, було розроблено нові методи, які мають в своїй основі ГТУ. Дані методи дозволяють виконувати лінеаризацію нелінійних систем управління за допомогою зворотного зв'язку у просторі “вхід - стан” та “вхід - вихід”. ГТУ дозволяє отримати еквівалентну лінійну модель на всій площині, тому, вона зараз активно розвивається та застосовується [3, $6-8]$.

Проте виконання таких перетворень призводить до необхідності виконання величезних об’ємів 
аналітичних розрахунків, які займають багато часу, та в яких легко допустити помилку $[1,3]$. Тому ГТУ звичайно застосовується для роботи з об'єктами, які описувалися системами диференційних рівнянь до шостого порядку. Тому, перекладення цієї задачі з людини на комп'ютерну техніку стало не питанням часу, а необхідністю. Адже використання спеціалізованого програмного забезпечення дозволило б зменшити кількість часу, який би витрачався на процес лінеаризації, а також зменшити кількість потенційних помилок, які могли виникнути внаслідок людського фактору [1, 3, 6-8].

Питанням створення програмного забезпечення, яке б мало можливість виконувати такі дії було присвячено увагу у роботі [1]. Більш того, програмне забезпечення було створено, і виконувало свої функціï, проте воно $є$ недосконалим адже має наступні мінуси. Дане програмне забезпечення [1] залежить від математичного пакету, адже напряму працює саме з нього, тому зміна функціоналу чи набору інструкцій в математичному пакеті може вплинути на загальну працездатність програмного забезпечення. Також, усі змінні та вхідні параметри закодовані у коді відповідних файлів, тому для того, щоб виконати певні зміни, чи виконати лінеаризацію іншого об'єкту, необхідно втручатися в програмний код та переписувати його, а це значно підвищує планку та вимоги до фахівця, який повинен буде працювати $з$ цією програмою. Це сильно ускладнює можливості використання даного програмного забезпечення [1, 3, 6 - 8].

Після отримання лінійної форми Бруновського для математичної моделі, постає задача пошуку функцій перетворення, що зв'язують змінні лінійної та нелінійної системи. Це також складна задача, яка потребує розв'язання систем рівнянь в часткових похідних, і яка потребує досить об'ємних розрахунків та при виконанні цієї задачі людиною, також може призводити до виникнення проблем через людський фактор. Саме тому, це також є серйозним етапом в виконанні перетворень, який необхідно автоматизувати та перекласти на розрахункові потужності комп’ютерної техніки [1, 3, 6 - 10].

3 поміж різних способів пошуку функцій перетворення, підходящим для інтеграції в програмне забезпечення є той, що використовує в своїй основі нейронні мережі з відповідною структурою $[1,3]$. В роботах інших науковців [1] було запропоновано використати структуру нейронної мережі на основі мереж типу АРТ, проте в рамках рішення цієї задачі в даній роботі пропонується використання нейронної мережі з більш простою структурою, яка має аналогічні можливості.

Отже, проблема $є$ досить серйозною та склад-

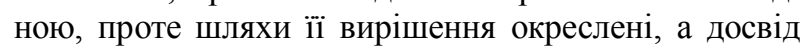
попередніх розробок може бути використаний в роботі над новою версією програмного забезпечення, що дозволить автоматизувати та пришвидшити процеси пов'язані з лінеаризацією та пошуком функцій перетворень, що пов'язують змінні нелінійної та лінійної математичних моделей.

Метою роботи $\epsilon$ розробка спеціалізованого програмного забезпечення, яке буде являти собою програмний компонент бортової комп'ютерної системи дизель-потяга, та дозволить автоматизувати процес перетворення нелінійної математичної моделі в лінійну математичну модель у формі Бруновського, а також процес пошуку функцій перетворення, що зв'язують змінні нелінійної та лінійної математичної моделей, а використання можливостей розробки додатків з графічним інтерфейсом максимально спростити задачу взаємодії користувача 3 даним програмним забезпеченням. Отже, основною метою роботи є заміна складних задач управління нелінійними об'єктами на більш прості задачі синтезу управлінь лінійними моделями в рамках ГТУ.

\section{Результати досліджень}

При проектуванні спеціалізованого програмного забезпечення було пройдено декілька етапів: аналіз попередніх розробок, створення відповідних вимог до програмного забезпечення, яке необхідно розробити, створення його структури, перевірка характеристик програмного забезпечення на відповідність вимог якості згідно з вимог ДСТУ ISO/IEC 25010:2016 [11], створення алгоритмів роботи програмного забезпечення, створення схеми графічного інтерфейсу, розробка, тестування. В рамках аналізу попереднього програмного забезпечення була розглянута робота [1], виявлено його недоліки та сформовано вимоги до нового програмного забезпечення. Зокрема було модернізовано блок-схему людино машинної системи, яка автоматизує аналітичні розрахунки в ГТУ (рис. 1), де нові блоки, що додані в програмне забезпечення позначені більш темним кольором.

Після того, як вимоги до нового програмного забезпечення було сформовано, та визначено, наступним етапом стала перевірка відповідності програмного забезпечення, що розробляється, критеріям якості згідно 3 вимогами ДСТУ ISO/IEC 25010:2016 [11]. Критерії, по яким відбувалася перевірка зображено на рис. 2. Перевірка програмного забезпечення довела, що воно відповідає вказаним на рис. 2 вимогам. Крім того, було виконано перевірку програмного забезпечення по таким критеріям (де було вказано на вдосконалення в порівнянні 3 попередньої версією):

1. Функціональність. Функціонал програмного забезпечення розширений за рахунок автоматизації процесів, пов'язаних з аналізом вхідних даних, їх обробкою та перетворення в представлення, яке більш зручне для подальшої обробки засобами програмування чи математичним пакетом.

2. Функціональність. Функціонал програмного забезпечення розширений за рахунок автоматизації процесів, пов'язаних $з$ аналізом вхідних даних, їх обробкою та перетворення в представлення, яке більш зручне для подальшої обробки засобами програмування чи математичним пакетом.

3. Надійність. Програмне забезпечення виконує тестування програмних модулів перед виконанням розрахунків.

4. Зручність. Графічний інтерфейс взаємодії 3 користувачем значно спростив процес роботи 3 програмним забезпеченням. 


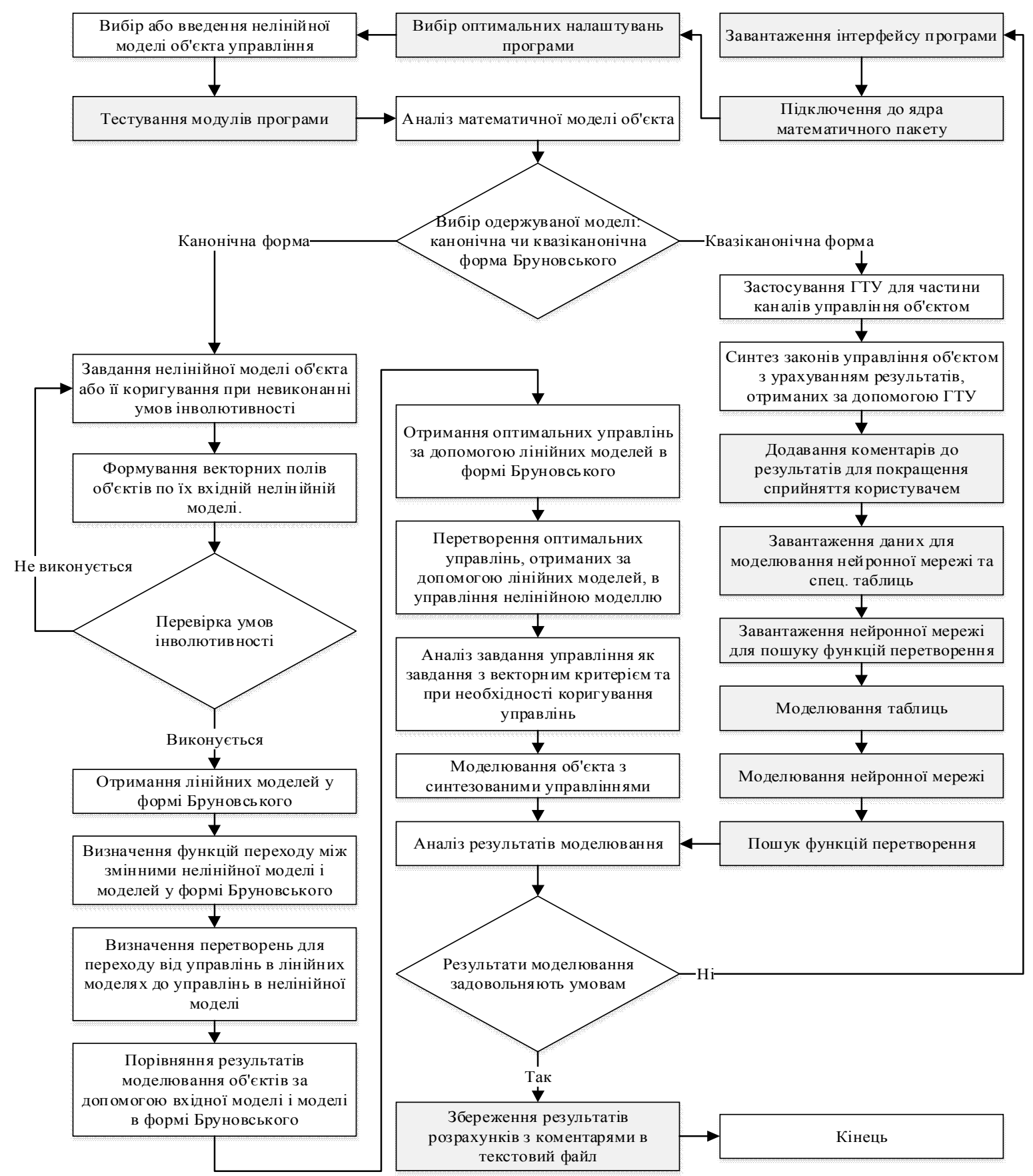

Рис. 1. Блок-схема людино машинної системи, яка автоматизує аналітичні розрахунки в ГТУ

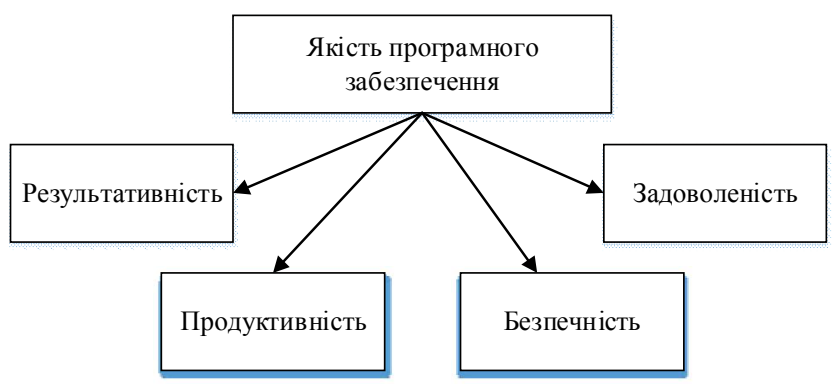

Рис. 2. Критерії якості програмного забезпечення згідно з ДСТУ ISO/IEC 25010:2016 [11]

5. Ефективність. Підвищена за рахунок оптимізації інструментами розробника, введення додаткових налаштувань для вмикання чи вимикання необхідного функціоналу.
6. Супроводженість. Структура програми складається $з$ окремих модулів, кожен з яких може бути швидко оновленим чи зміненим без виконання змін в інших модулях програмного забезпечення.

7. Мобільність. Програмне забезпечення являє собою виконавчий файл та декілька бібліотек до нього, тому може бути просто перенесене на інший комп'ютер, або запаковане в інсталятор для більш зручного виконання інсталяції у разі необхідності встановлення даного програмного забезпечення на інших робочих станціях.

Під час проектування алгоритмів роботи програмного забезпечення, так створення його структури, було прийнято рішення поділити програмне забезпечення на відповідні модулі, які б дозволили виконати поставлене завдання, проте були б незале- 
жними, що дозволило б без проблем оновлювати програмне забезпечення не цілком, а частинами, що значно спростило б цей процес, підвищило надійність та стабільність роботи програми, а також дозволило, відносно просто, додавати нові можливості та новий функціонал. Схема модулів програмного забезпечення зображена на рис. 3.

Розглянемо функції, які виконують блоки програмного забезпечення окремо:

1. Блок завантаження даних. Відповідає за отримання даних зі спеціальних текстових полів інтерфейсу користувача та переведення їх з текстового вигляду в програмне представлення.

2. Блок тестування. Виконує тестування блоків програмного забезпечення, перевіряє правильність перетворень тестових наборів даних.

3. Компонент утиліт. Використовується всередині програмного забезпечення для переведення даних програми $з$ одного вигляду в інший. Містить функції для перегортання матриць, переведення їх в форму масиву чи тексту, тощо.

4. Розрахунковий блок. Виконує основні розрахунки, пов'язані з диференціюванням, розрахунком дужок Лі, отримання результату у формі Бруновського.

5. Блок нейронної мережі пошуку функцій перетворення. Виконує процеси пов'язані 3 роботою нейронної мережі під час пошуку функцій перетворення, що пов'язують змінні нелінійної та лінійної математичних моделей.

6. Блок роботи 3 файловою системою. Виконує функції взаємодії з файловою системою для збереження результатів роботи програми, завантаження вхідних даних, тощо.

Після того, як розробка і тестування роботи програмного забезпечення була завершена, необхідно було переконатися в правильності роботи програмного забезпечення. Для цього, було виконано лінеаризацію математичної моделі, а потім порівняно результати ії моделювання для нелінійної та лінійної математичної моделі у формі Бруновського відповідно. Результати порівняння вихідних даних показали

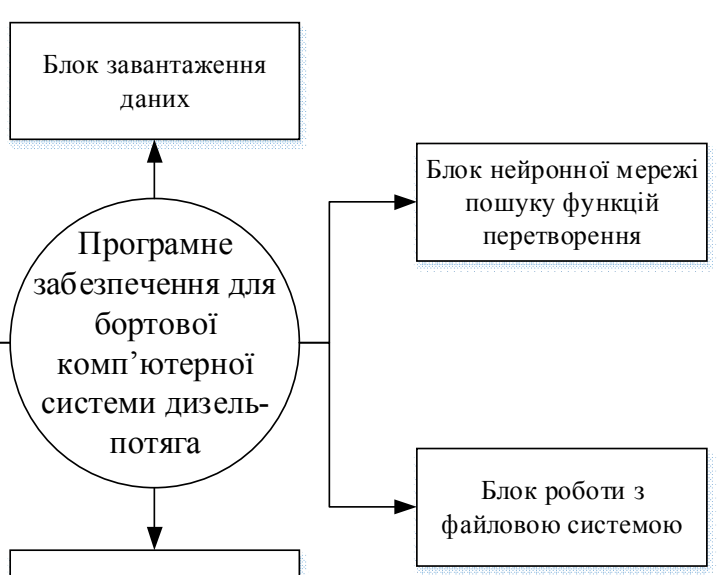

Розрахунковий блок

ис. 3. Структура модулів програмного забезпечення для бортової комп'ютерної системи дизель-потяга

повне співпадіння, що дозволяє стверджувати, що програмне забезпечення функціонує правильно. Можливості програмного забезпечення для бортової комп'ютерної системи, яке було розроблено, дозволяє перейти до наступного глобального етапу - це вирішення питання оптимального руху потяга по маршруту. Адже наявність можливості внесення змін в математичну модель та можливість, майже відразу, отримувати результат у вигляді ії лінійного еквіваленту - це те, що дозволяє робити велику кількість експериментів, багаторазово виконувати прорахунки для одного і того ж відрізку шляху, чи маршруту в цілому, що дозволить знайти оптимальний режим руху дизель-потяга по маршруту його слідування з поміж отриманих наборів даних.

\section{Висновок}

Таким чином, у статті описано суть проблеми, пов'язаної зі складністю проведення лінеаризації, i як наслідок, для іiї вирішення запропоновано розроблене програмне забезпечення, процес проектування, створення його структури, перевірки на відповідність вимогам якості, тестування, описано в даній статті. Результати використання програмного забезпечення підтвердили його роботоспроможність i правильність обраних алгоритмів та технологій. Звідси, можна виділити, що в рамках даної розробки було створено більш досконале програмне забезпечення, яке в більш короткий час та більш простий спосіб здатне вирішувати поставлені задачі.

\section{СПИСОК ЛІТЕРАТУРИ}

1. Заковоротный А. Ю. Синтез автоматизированной системы управления подвижным составом на основе геометрической теории управления и нейронных сетей [Электронный ресурс]: дис. ... д-ра техн. наук: спец. 05.13.07 / Александр Юрьевич Заковоротный; науч. консультант Дмитриенко В. Д. ; Нац. техн. ун-т “Харьков. политехн. ин-т”. - Харьков, 2017. - 433 с. - Библиогр.: с. $326-358$.

2. Liu, B. \& Gao, C. / Key Technologies of the Independent and Innovative Communications-Based Train Control Systems in China / Urban Rail Transit (2016) 2: 28. doi:10.1007/s40864-016-0035-Z

3. Дмитриенко В. Д. Моделирование и оптимизация процессов управления движением дизель-поездов / В. Д. Дмитриенко, А. Ю. Заковоротный. - Х.: Изд. центр «НТМТ», 2013. - 248 с.

4. Verma, A. \& Pattanaik, K.K. / Multi-agent communication-based train control system for Indian railways: the behavioural analysis / Journal of Modern Transportation (2015) 23: 272. doi:10.1007/s40534-015-0083-1

5. Albrecht, T. (2013), "Human factor challenges in the development of a driver advisory system for regional passenger trains", Rail human factors: supporting reliability, safety and cost reduction, Taylor \& Francis, London, pp 129-138. 
6. Программная компонента для поиска решений системы уравнений в частных производных в ГТУ методом группового учёта аргументов / В.Д. Дмитрієнко, А.Ю. Заковоротный, С.Ю. Леонов, Д.М. Главчев // Вісник Національного технічного університету “ХПІ”. Серія: Інформатика та моделювання. - Х.: НТУ “ХПІ”, 2019. - №13 (1338). - С. 61 - 72.

7. Аграчев А.А., Сачков Ю.Л. Геометрическая теория управления: моногр. - М.: ФИЗМАТЛИТ, 2015. - 392 с.

8. Исследование метода поиска функций преобразования нелинейных систем к эквивалентным линейным в геометрической теории управления / В.Д. Дмитрієнко, А.Ю. Заковоротный, Н.В. Мезенцев, Д.М. Главчев // Вісник Національного технічного університету “ХПІ”. Серія: Інформатика та моделювання. - Х.: НТУ “ХПІ”, 2018. - № 42 (1318). - С. 20 - 35.

9. Charu C. Aggarwal Neural Networks and Deep Learning: A Textbook.- IMB T.J. Watson Research Center, 2018. - 94 c.

10. Главчев Д.М. Нейронная сеть, распознающая группы изображений / В.Д. Дмитриенко, С.Ю. Леонов, Д.М. Главчев / Вісник НТУ “ХПІ”. - Харків: НТУ “ХПГ”, 2015, № 32 (1141). - С. 42 - 50.

11. ДСТУ ISO/IEC 25010:2016 Інженерія систем і програмних засобів. Вимоги до якості систем і програмних засобів та iï оцінювання. Моделі якості системи та програмних засобів (ISO/IEC 25010:2011, IDT).

Рецензент: д-р техн. наук, проф. О. О. Можаєв, Харківський національний університет внутрішніх справ, Харків

Received (Надійшла) 30.08.2019

Accepted for publication (Прийнята до друку) 25.09.2019

\section{Программные компоненты бортовой компьютерной системы дизель-поезда}

\section{Д. М. Главчев}

При решении задач в рамках геометрической теории управления возникают проблемы, связанные со сложностью выполнения расчета производных Ли, проверки распределений на инволютивность, поиска функций преобразования, которые связывают переменные и уравнения линейной и нелинейной моделей. При выполнении этих операций человеком возникает потребность в выполнении слишком объемных аналитических расчетов, которые могут стать причиной отказа от применения геометрической теории управления. Решить эту проблему можно с помощью использования специализированного программного обеспечения. Рассматривается программное обеспечение для бортовой компьютерной системы дизельпоезда, которое способно автоматизировать необходимые расчеты, чем существенно сократить время выполнения линеаризации и поиска функций преобразования для математических моделей за счет использования мощностей компьютерной техники и нейронных сетей. Целью работы является разработка специализированного программного обеспечения для выполнения линеаризации математических моделей и поиска функций преобразования за счет использования нейронных сетей и возможностей языка программирования, имеет графический интерфейс для взаимодействия с пользователем. Результаты. С помощью возможностей современных языков программирования на основе предложенных алгоритмов обработки данных и нейронных сетей предложенной структуры, разработано специализированное программное обеспечение для выполнения преобразования нелинейных математических моделей в линейную форму Бруновского и поиска функций преобразования. При использовании разработанного программного обеспечения увеличивается скорость выполнения процесса линеаризации, поиска функций преобразования, а графический интерфейс и комментарии, которые освещает программное обеспечение в процессе работы дают возможность оперировать пользователям, которые не имеют специальной подготовки. Сравнение результатов моделирования нелинейной математической модели линейной математической моделью в форме Бруновского показало полное совпадение и подтвердило правильность теоретических положений и эквивалентности, нелинейной и линейной математический моделей. Выводы. Разработано специализированное программное обеспечение для автоматизации аналитических преобразований геометрической теории управления, решения систем уравнений в частных производных, для определения функций преобразований, связывающих переменные линейной и нелинейной моделей. Промоделирован ряд объектов, которые показали работоспособность программного обеспечения.

Ключевые слова: программное обеспечение, форма Бруновского, математическая модель, нейронные сети, геометрическая теория управления.

\section{Software components of the on-board computer system of a diesel train}

\section{Hlavchev}

When solving problems within the framework of the geometric theory of control, problems arise related to the difficulty of calculating the Lie derivatives, checking distributions for involutivity, searching for transformation functions that relate variables and equations of linear and nonlinear models. When performing these operations, a person has a need to perform too voluminous analytical calculations, which may cause the refusal to apply the geometric theory of control. This problem can be solved by using specialized software. We consider software for the on-board computer system of a diesel train, which is able to automate the necessary calculations, thereby significantly reducing the time it takes to linearize and search for the conversion functions for mathematical models by using the power of computer technology and neural networks. The aim of the work is the development of specialized software to perform linearization of mathematical models and search for conversion functions through the use of neural networks and the capabilities of a programming language, has a graphical interface for user interaction. Results. Using the capabilities of modern programming languages based on the proposed data processing algorithms and neural networks of the proposed structure, specialized software has been developed for converting non-linear mathematical models into the linear Brunovsky form and searching for conversion functions. When using the developed software, the speed of the linearization process, the search for conversion functions increases, and the graphical interface and comments that the software illuminates during operation make it possible to operate users who do not have special experience. A comparison of the results of modeling a nonlinear mathematical model with a linear mathematical model in the form of Brunovsky showed complete coincidence and confirmed the correctness of the theoretical positions and equivalence of the nonlinear and linear mathematical models. Conclusions. Specialized software has been developed for automating analytical transformations of the geometric control theory, for solving systems of partial differential equations, for defining transformation functions connecting variables of linear and nonlinear models. A number of objects were modeled that showed the operability of the software.

Keywords: software, Brunovsky's form, mathematical model, neural networks, geometrical control theory. 